\title{
Colchicine induces apoptosis in HT-29 human colon cancer cells via the AKT and c-Jun $\mathrm{N}$-terminal kinase signaling pathways
}

\author{
ZHEN HUANG, YE XU and WEI PENG
}

Department of General Surgery, Shanghai Traditional Chinese Medicine-Integrated Hospital, Shanghai 200082, P.R. China

Received September 17, 2014; Accepted June 5, 2015

DOI: $10.3892 / \mathrm{mmr} .2015 .4222$

\begin{abstract}
Colchicine is a natural compound, which belongs to the botanical family Colchicaceae and prevents growth of cancer cells via antimitotic activity by interacting with microtubules. Although numerous studies have demonstrated that the effect of colchicine on cell apoptosis is mediated by the activation of caspase-3, the signaling pathways involved in the process remain unknown. In the current study, evidence is presented regarding the missing information using HT-29 human colon cancer cells. The effect of colchicine on apoptosis in HT-29 cells and the apoptosis-associated signaling pathways were determined using various methods, including cell viability assay, Annexin V/propidium idodide (PI) binding, PI staining, Hoechst 33342 staining, mitochondrial membrane potential $(\Delta \psi \mathrm{m})$ assay, reactive oxygen species (ROS) assay and western blot analysis. Colchicine was observed to induce a dose-dependent reduction in cell viability in HT-29 cells and early apoptosis occurred when the cells were treated with $1 \mu \mathrm{g} / \mathrm{ml}$ colchicine. Furthermore, colchicine treatment induced a loss of $\Delta \psi \mathrm{m}$, increased ROS production, activated caspase-3, upregulated BAX expression and downregulated Bcl-2 expression, which evidenced the colchicine activity on apoptosis, potentially by acting via the intrinsic apoptotic signaling pathway. Colchicine increased phosphorylation of p38, although not phosphorylation of extracellular signalregulated kinase and c-Jun N-terminal kinase, which indicates that colchicine activates the p38 signaling pathway in order to induce cell apoptosis. Therefore, colchicine exhibited significant growth inhibition of the HT-29 colon cancer cell line and induced apoptosis in the cells via the mitochondrial pathway, which is regulated by p38 signaling pathways.
\end{abstract}

Correspondence to: Dr Wei Peng, Department of General Surgery, Shanghai Traditional Chinese Medicine-Integrated Hospital, 230 Baoding Road, Houkou, Shanghai 200082, P.R. China

E-mail: dzbmwpengwei@126.com

Key words: colchicine, colon cancer, apoptosis, AKT, c-Jun $\mathrm{N}$-terminal kinase

\section{Introduction}

Colon cancer is a particularly common type of cancer with 655,000 mortalities per year $(1,2)$. Worldwide, colon cancer remains a major cause of cancer-related mortality $(3,4)$. Despite recent developments of novel treatment strategies, the five-year survival rate of advanced colon cancer patients remains particularly poor, due to insensitivity to chemotherapy and susceptibility to recurrence (5-7). Thus, novel therapeutic agents are required to treat colon cancer.

Numerous microtubule-targeting agents that are currently approved or are in clinical development (including paclitaxel, vinblastine, vincristine, colchicine and combretastatin) are plant-derived compounds (8). Cochicine, which is a natural compound, can be isolated from either Colchicum autumnale (meadow saffron) or Gloriosa superba (glory lily), which belong to the lily family (9). Colchicine prevents growth of cancer cells by antimitotic activity through interacting with microtubules, and may contribute to the establishment of improved cancer therapies (10-11). Furthermore, colchicine preferentially binds to unpolymerized tubulin heterodimers in solution, forming a stable complex that effectively inhibits microtubule dynamics upon binding to microtubule ends (12). Colchicine causes microtubule depolymerization by inhibiting lateral contacts between protofilaments (13). Although colchicine exerts potent microtubule depolymerization activity and possesses antimitotic properties, its mechanism of inducing colon cancer cell apoptosis remains unclear.

The aim of the present study was to investigate the molecular mechanism by which colchicine induces apoptosis in colon cancer. HT-29 colon cancer cells were treated with varying concentration of colchicine and cell proliferation was analyzed using a Cell Counting Kit-8 (CCK-8). Apoptosis was assayed by flow cytometry and Hoechst 33342 straining. In addition, the mitochondrial membrane potential $(\Delta \psi \mathrm{m})$ and reactive oxygen species (ROS) were assayed by flow cytometry. In addition, apoptosis-associated proteins were examined by western blot. The present study investigated the apoptosis-inducing effects of colchicine in colon cancer cells as well as the underlying mechanism.

\section{Materials and methods}

Reagents. Purified colchicine (98.79\%) was procured from Nanjing Zelang Medical Technological Co. Ltd. (Nanjing, 
China). Antibodies for p38 (cat. no. 9212), phosphorylated (P)-p38 (cat. no. 4092), c-Jun N-terminal kinase (JNK) (cat. no. 9252), P-JNK (cat. no. 81E11), extracellular signal-regulated kinase (ERK) (cat. no. 9107), P-ERK (cat. no. 4370), AKT (cat. no. 9272) and P-AKT (cat. no. 587F11) were purchased from Cell Signaling Technology, Inc. (Danvers, MA, USA) and GAPDH (cat. no. ab181602) was obtained from Thermo Fisher Scientific, Inc. (Pittsburgh, PA, USA). Antibodies for caspase-3 (cat. no. ab32499), caspase-9 (cat. no. BMS1041) and Apaf-1 (cat. no. MA515743) were purchased from Abcam (Cambridge, MA, USA) and Hoechst 33258 and an AlexaFluor 488-conjugated Annexin V Apoptosis Detection kit were obtained from Molecular Probes Life Technologies (Carlsbad, CA, USA).

Cell culture. The human colon cancer HT-29 cell line was obtained from Shanghai Institute of Cell Biology (Shanghai, China). Cells were cultured in RPMI-1640 medium with 10\% fetal bovine serum (Gibco Life Technologies, Carlsbad, CA, USA), $100 \mathrm{U} / \mathrm{ml}$ penicillin $\mathrm{G}$ and $100 \mu \mathrm{g} / \mathrm{ml}$ streptomycin in an incubator at $37^{\circ} \mathrm{C}, 100 \%$ humidity and an atmosphere of $5 \%$ $\mathrm{CO}_{2}$. The growth medium was replaced every 2-3 days.

CCK-8 assay. The CCK-8 (Dojindo Molecular Technologies, Inc., Shanghai, China) was used to determine cell viability according to the manufacturer's instructions. Cells were plated at a density of $5 \times 10^{3}$ cells/well in 96-well microtiter plates and cultured overnight at $37^{\circ} \mathrm{C}$ in a humidified incubator with a 5\% $\mathrm{CO}_{2}$ atmosphere. Following treatment with colchicine for 24 , 48 or $72 \mathrm{~h}$, the culture medium was replaced with $100 \mu \mathrm{l}$ fresh medium followed by the addition of $10 \mu \mathrm{l} \mathrm{CCK}-8$ solution. The cells were incubated for a further $2 \mathrm{~h}$ at $37^{\circ} \mathrm{C}$, and the optical density was recorded at an absorbance of $450 \mathrm{~nm}$. All experiments were performed in triplicate.

Cell apoptosis assay. Cell apoptosis was detected by an Annexin V-(fluorescein isothiocyanate) FITC/propidium iodide (PI) Apoptosis Detection kit I (BD Biosciences, Franklin Lakes, NJ, USA) according to the manufacturer's instructions. Cells were seeded in 6-well plates at the density of $1 \times 10^{5}$ cells/well. Following incubation for $24 \mathrm{~h}$ at $37^{\circ} \mathrm{C}$, colchicine was added to the 6 -well plate and incubated for another $24 \mathrm{~h}$. Cells were collected and washed twice with phosphate-buffered saline (PBS) and resuspended, subsequently aliquots of $1 \times 10^{5}$ cells were transferred into $5-\mathrm{ml}$ culture tubes in $100 \mu 11 \mathrm{X}$ binding buffer (BD Biosciences). Annexin V-FITC (5 $\mu \mathrm{l})$ and $5 \mu \mathrm{l}$ PI were added to the resuspended cells. Following incubation at room temperature for $15 \mathrm{~min}$ in the dark, $400 \mu \mathrm{l}$ binding buffer was added to the resuspended cells. Flow cytometry (FACSCalibur; BD Biosciences) was used to assess the apoptotic cells. The quantitation of apoptotic cells was calculated using CellQuest Pro software version 5.1 (BD Biosciences).

Hoechst staining. The nuclei were stained using Hoechst 33342 dye (Molecular Probes Life Technologies) to visualize nuclear morphology, as well as the induction of apoptosis. Following treatment with colchicine, the cells were incubated with $10 \mu \mathrm{M}$ Hoechst 33342 dye for $10 \mathrm{~min}$ at $37^{\circ} \mathrm{C}$. Images were obtained using a Leica DM IRB inverted fluorescence microscope

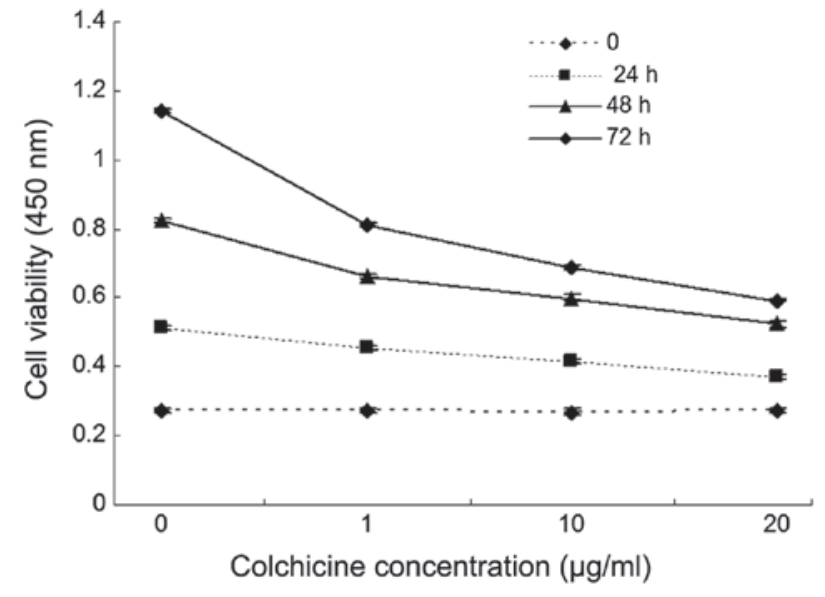

Figure 1. Colchicine inhibited cell viability in HT-29 cells. HT-29 cells were treated with $0,1,10$ and $20 \mu \mathrm{g} / \mathrm{ml}$ colchicine for $0,24,48$ and $72 \mathrm{~h}$. Cell viability was determined using a Cell Counting Kit- 8 assay to calculate the growth.

(2886; Leica Microsystems GmbH, Wetzlar, Germany; magnification, $\mathrm{x} 400$ ).

Mitochondrial membrane potential $(\Delta \psi m)$ analysis. $\Delta \psi \mathrm{m}$ was analyzed using a JC-1 $\Delta \psi \mathrm{m}$ assay kit (Cayman Chemical Company, Ann Arbor, MI, USA), according to the manufacturer's instructions. In brief, HT-29 cells were incubated with $0,1,10$ and $20 \mu \mathrm{g} / \mathrm{ml}$ colchicine for $12 \mathrm{~h}$, centrifuged at $1,200 \mathrm{x} \mathrm{g}$ for $5 \mathrm{~min}$ and resuspended in RPMI-1640 medium. Following the addition of JC-1 to each well, the cells were incubated for an additional $30 \mathrm{~min}$ at $37^{\circ} \mathrm{C}$. After washing with PBS, the stained cells were assayed using a flow cytometer (FACSCalibur; BD Biosciences).

Mitochondrial isolation and measurement of ROS production. Mitochondria were isolated from the untreated HT-29 cells to investigate the effect of colchicine on ROS production and the possibility of the mitochondria as a target of colchicine. Cells were washed twice in cold PBS, resuspended in hypotonic buffer (1 mM EDTA, $5 \mathrm{mM}$ Tris- $\mathrm{HCl}(\mathrm{pH} 7.5), 210 \mathrm{mM}$ mannitol, $70 \mathrm{mM}$ sucrose, $10 \mu \mathrm{M}$ Leu-pep, $10 \mu \mathrm{M}$ Pep-A and100 $\mu \mathrm{M}$ phenylmethanesulfonylfluoride; Molecular Probes Life Technologies), homogenized, then centrifuged at $500 \mathrm{x} \mathrm{g}$ for $5 \mathrm{~min}$ at $4^{\circ} \mathrm{C}$ to pellet the nuclear fraction. The supernatant was centrifuged at $12,000 \mathrm{rpm}$ for $15 \mathrm{~min}$ at $4^{\circ} \mathrm{C}$. The cytosolic supernatant was disposed of and the pellet (containing mitochondria) was resuspended in cold reaction buffer and treated with $10 \mu \mathrm{M}$ colchicine. Amplex Red (Molecular Probes Life Technologies) in combination with horse-radish peroxidase was used to assess mitochondrial ROS production. Fluorescence (excitation, $560 \mathrm{~nm}$; emission, $590 \mathrm{~nm}$ ) was measured using a spectrofluorometer (SpectraMax Gemini XS; Molecular Devices, LLC, Sunnyvale, CA, USA) every $5 \mathrm{~min}$ for $5 \mathrm{~h}$. The readings were analyzed using GraphPad Prism 6.0 (GraphPad Inc., La Jolla, CA, USA) and expressed as relative fluorescence units per microgram of protein. The data are representative of three independent experiments.

Statistical analysis. All experiments were repeated at least three times and values are expressed as the mean \pm standard 
A

Colchicine $(\mu \mathrm{g} / \mathrm{ml})$

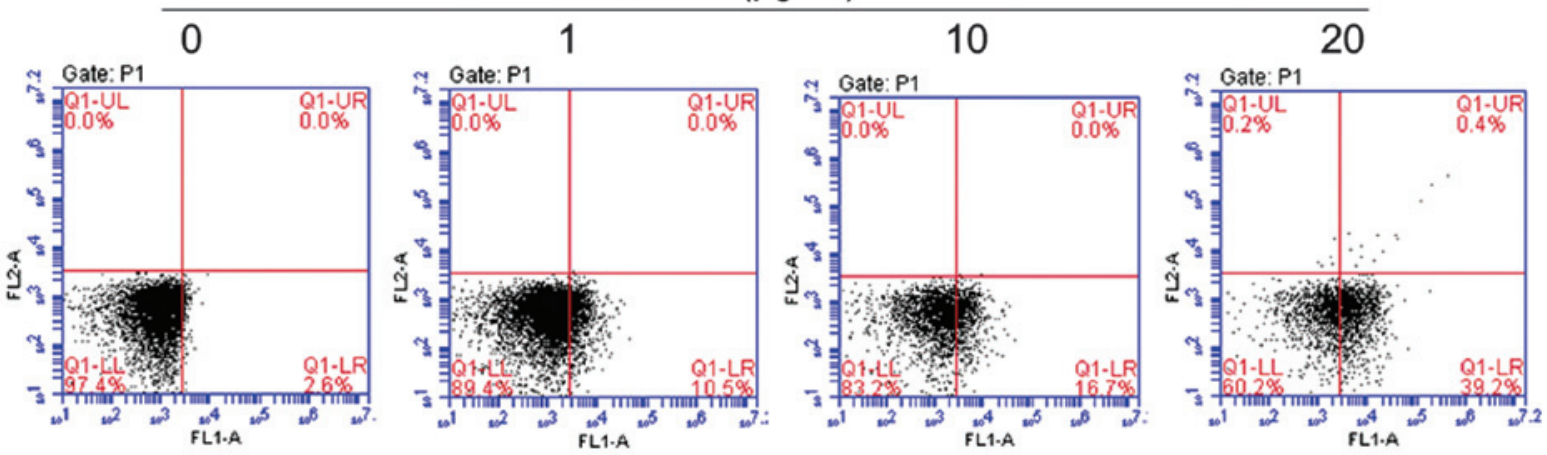

B

Colchicine $(\mu \mathrm{g} / \mathrm{ml})$

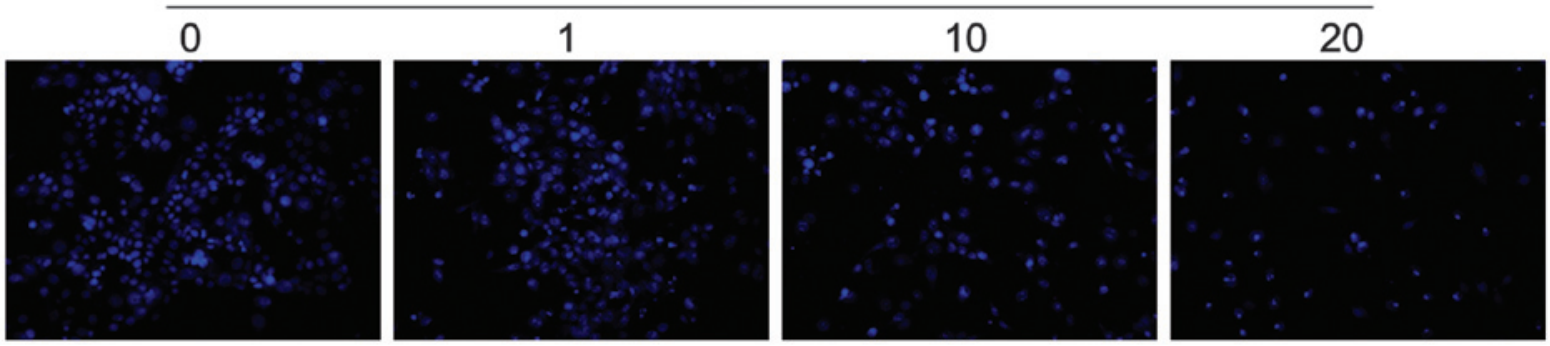

Figure 2. Colchicine induced HT-29 cell apoptosis. (A) The HT-29 cells treated with colchicine were subjected to flow cytometry to measure cell apoptosis following staining with Annexin V/propidium iodide. The cell apoptosis data presented is representative of a minimum of three independent experiments and the dot plots are shown for the analyzed cells. (B) Morphology of apoptotic cells. HT-29 cells were exposed to varying concentrations $(0,1,10$ and $20 \mu \mathrm{g} / \mathrm{ml}$ ) of colchicine for $24 \mathrm{~h}$. Cell apoptosis was assayed by Hoechst 33258 fluorescence staining to detect chromosomal condensation and nuclear fragmentation.

A

Colchicine $(\mu \mathrm{g} / \mathrm{ml})$

0
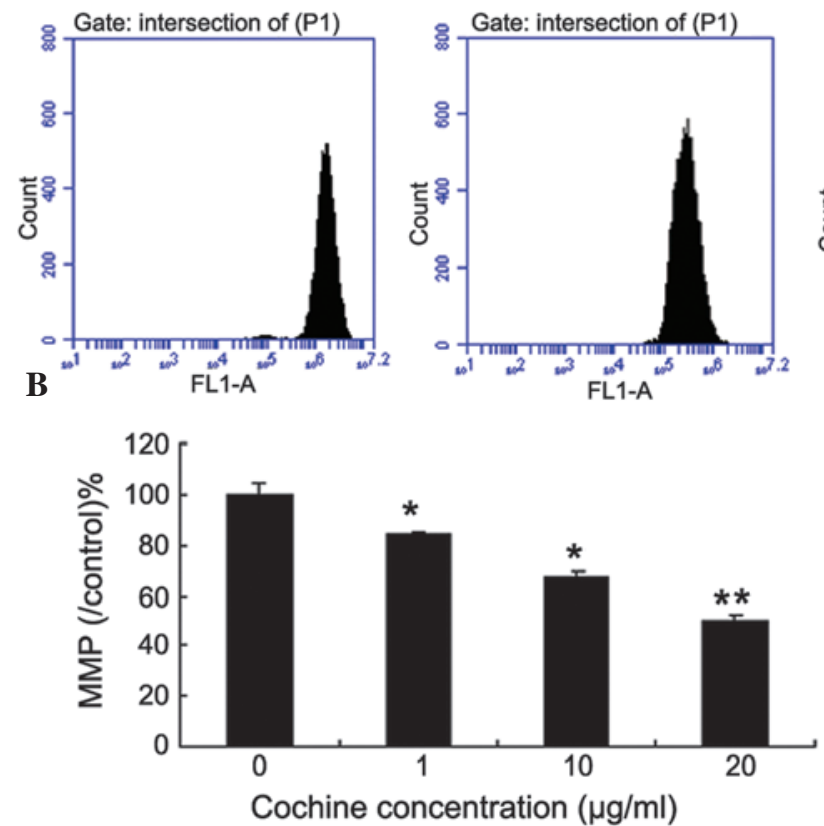

10

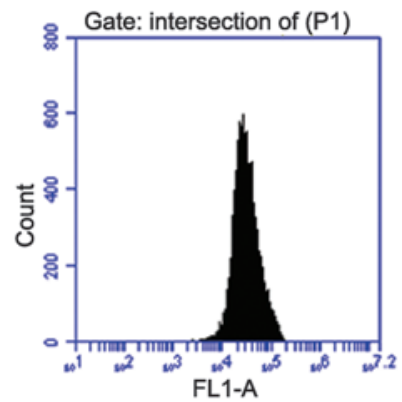

20

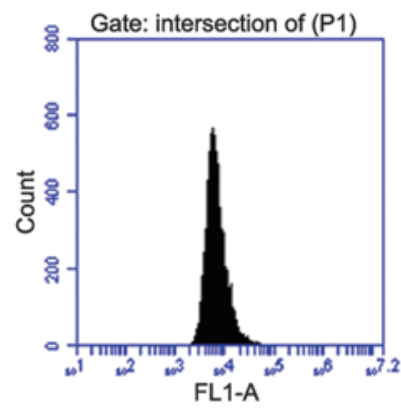
JC-1-stained cells were mounted onto microscope slides in mounting medium. (B) The colchicine-treated cells exhibited a significant and dose-dependent decrease in $\Delta \psi \mathrm{m}$ when compared with the control group. MMP, mitochondrial membrane potential.

error. Statistical analysis was performed using two-way analysis of variance with GraphPad Prism 6.0 software. $\mathrm{P}<0.05$ was considered to indicate a statistically significant difference between values. 
A Colchicine $(\mu \mathrm{g} / \mathrm{ml})$

0

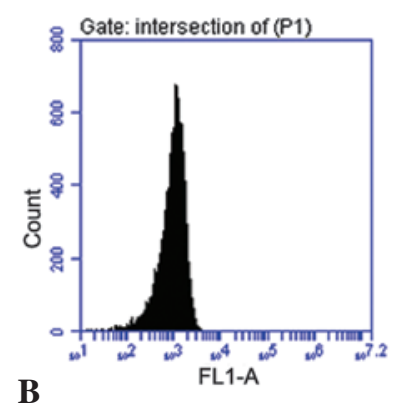

1

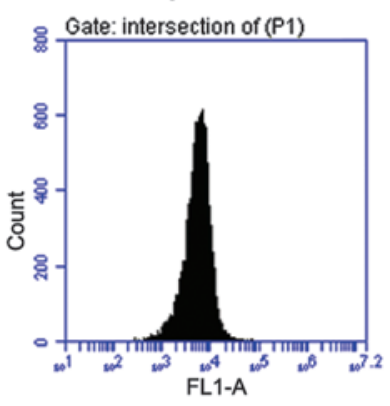

ROS

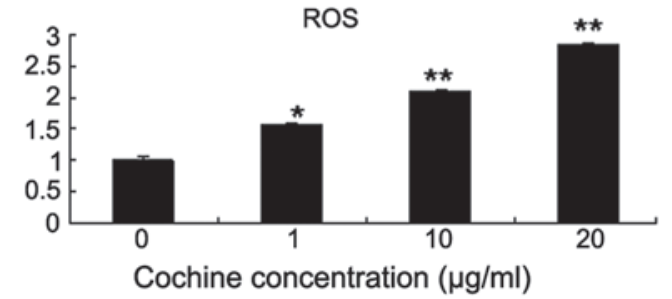

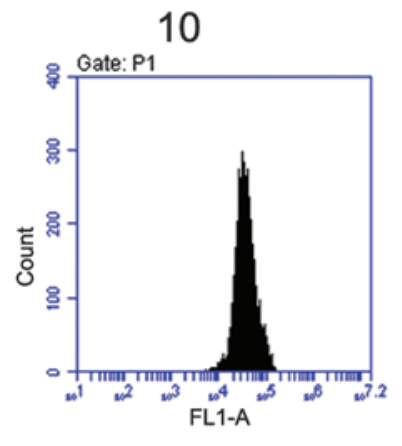

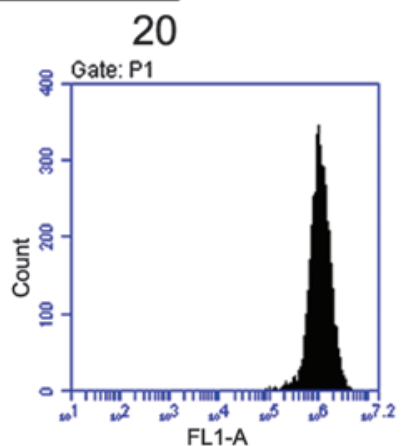

Figure 4. Colchicine increases ROS production in HT-29 cells. (A) Treatment with colchicine (0, 1,10 and $20 \mu \mathrm{g} / \mathrm{ml}) \mathrm{for} 12 \mathrm{~h}$. (B) Colchicine increased ROS production in the HT-29 cells. The HT-29 cells were stained and detected by flow cytometry. Amplex Red in combination with horse-radish peroxidase was used to assess mitochondrial ROS production. ROS, reactive oxygen species.

\section{Results}

Colchicine inhibits proliferation of colon cancer cells. Colchicine inhibits the proliferation of colon cancer cells in vitro. HT-29 cells were incubated with increasing doses of colchicine $(0,1,10$ and $20 \mathrm{ug} / \mathrm{ml})$ or a vehicle control for $48 \mathrm{~h}$, and cell viability was measured using a CCK-8 assay. As shown in Fig. 1, colchicine significantly inhibited the proliferation of HT-29 cells when the cells were treated with $>20 \mu \mathrm{g} / \mathrm{ml}$ colchicine, compared with the control, and the cell viability decreased significantly in a dose-dependent manner. In addition, the result revealed that colchicine inhibited HT-29 cell proliferation in a time-dependent manner.

Colchicine induces apoptosis of colon cancer cells. Colchicine inhibited cell proliferation and induced cellular death in colon cancer cells; however, the underlying mechanisms have not been investigated in detail. To establish whether this treatment could also induce apoptosis in HT-29 cells, flow cytometry was used to assess the percentage of apoptotic cells induced by colchicine treatment. Similar to the results of the cell viability assay, colchicine concentrations of $>20 \mu \mathrm{g} / \mathrm{ml}$ significantly increased cell apoptosis compared with the respective control cells (Fig. 2A), and the increase was dose- and time-dependent. Treatment of colchicine at doses of 10 and $20 \mu \mathrm{g} / \mathrm{ml}$ for $24 \mathrm{~h}$ significantly increased the number of early apoptotic cells (Fig. 2A: Q1-LR) in a dose-dependent manner compared with control cells. The significant induction of apoptosis indicated the anticancer effect of colchicine against HT-29 cells. The colchicine-induced apoptosis in the HT-29 cells was morphologically identified using fluorescence staining with Hoechst 33258 (Fig. 2B); chromosomal condensation and nuclear fragmentation were observed in the colchicine-treated cells.

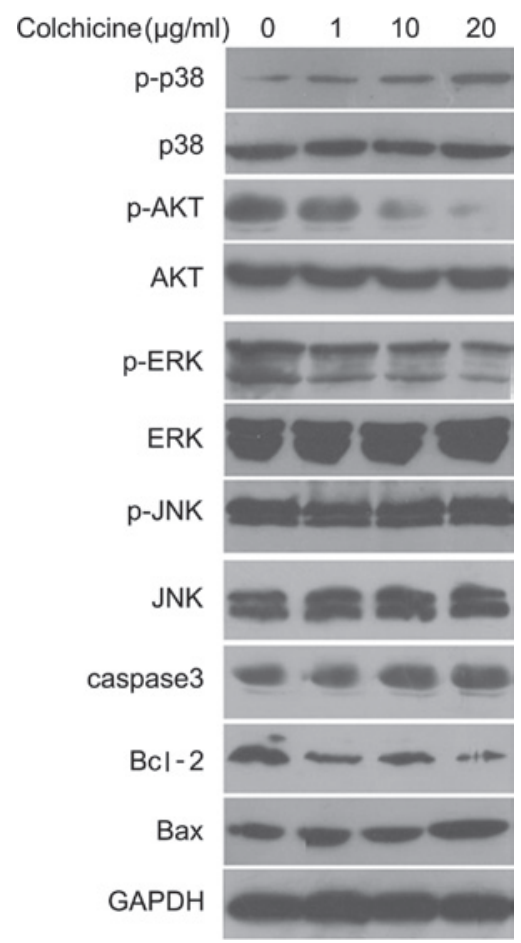

Figure 5. Effects of colchicine on expression of key proteins involved in cell apoptosis. Treatment with colchicine $(0,1,5$ and $10 \mu \mathrm{g} / \mathrm{ml})$ for $12 \mathrm{~h}$. Total protein from the HT-29 cells was extracted for western blot analysis. p, phosphorylated; ERK, extracellular signal-regulated kinase; JNK, c-Jun N-terminal kinase.

Colchicine induces colon cancer cell apoptosis via the mitochondrial pathway. During the apoptotic process, mitochondrial membrane pores open and $\Delta \psi \mathrm{m}$ is disrupted. As shown in Fig. 3, the JC-1 staining data demonstrates that colchicine-treated cells exhibited a significant decrease in the 
$\Delta \psi \mathrm{m}$ in a dose-dependent manner, when compared with the control cells.

Colchicine increases ROS production in HT-29 cells. Mitochondria are critical in the initiation and progression of cell death processes and, therefore, may serve as targets for numerous chemotherapeutic agents. To determine whether the mitochondria are involved in colchicine-induced cell death, mitochondria were isolated from HT-29 cells and treated with 0, 1, 10 or $20 \mu \mathrm{g}$ colchicine for $12 \mathrm{~h}$. Staining with Amplex Red in combination with horse-radish peroxidase followed by flow cytometric analysis of the fluorescence showed that colchicine increased ROS production of HT-29 cells in a dose-dependent manner (Fig.4).

Colchicine promotes colon cancer cell apoptosis vua activation of the p38 pathway. The expression of apoptosis-associated proteins and the phosphorylation of kinases was detected by western blot and hybridization to clarify the mechanism of HT-29 cell apoptosis induced by colchicine treatment. As shown in Fig. 5, treatment with colchicine $(0,1,10$ and $20 \mu \mathrm{g} / \mathrm{ml})$ for $12 \mathrm{~h}$ increased $\mathrm{p} 38$ phosphorylation dose-dependently and decreased AKT phosphorylation. However, colchicine treatment did not significantly affect phosphorylation of the JNK and ERK proteins. Furthermore, treatment with colchicine for $12 \mathrm{~h}$ evidently increased the protein expression of caspase-3 and Bax, and decreased Bcl-2 expression in a dose-dependent manner when compared with the control group (Fig. 5).

\section{Discussion}

In recent years, numerous reports have indicated that colchicine exhibits potent antitumor activity against various tumor cell lines, such as liver, colon, gastric and lung cancer cells (14-19). In the present study, the inhibitory effect of colchicine on HT-29 colon cancer cells was investigated and the possible molecular mechanism involved was elucidated. The results revealed that colchicine inhibited HT-29 cell proliferation in a time- and dose-dependent manner. Flow cytometric analysis with Annexin V/PI staining demonstrated that colchicine treatment with doses ranging between 1 and $20 \mu \mathrm{g} / \mathrm{ml}$ induced apoptosis and increased DNA fragmentation of HT-29 cells in a dose-dependent manner. The data regarding cell viability, cell apoptosis and DNA fragmentation obtained in the present study, indicates that colchicine penetrates HT-29 cells and destroys mitochondria membrane integrity, which consequently results in cell apoptosis.

Mitochondria are crucial in the complex process of apoptosis (20). During this process, mitochondrial membrane pores are opened, resulting in the loss of $\Delta \psi \mathrm{m}$ (21). This loss of $\Delta \psi \mathrm{m}$ causes an increase in the permeability of the mitochondrial membrane, followed by the release of proapoptotic molecules, such as cytochrome $c$. The release of cytochrome $c$ from the mitochondrial membrane interacts with adenosine triphosphate (ATP), Apaf-1 and caspase-9, and subsequently activates caspase-3, which elicits caspase-dependent apoptotic cell death (22). The current study demonstrated that colchicine increases $\Delta \psi \mathrm{m}$.

Activation of mitogen activated protein kinase (MAPK) is associated with cell cycle arrest and apoptosis induction.
There are three known parallel pathways of the MAPK family: ERK, JNK and p38 (23). In the present study, the phosphorylation levels of ERK, JNK and p38 were detected by western blotting, however, only p38 phosphorylation was observed to increase as a result of colchicine treatment. The present study demonstrated the effect of colchicine on JNK signaling in HT-29 cells. JNK promotes Bax translocation to the mitochondria and the release of cytochrome $c$ from the mitochondria. The released cytochrome $c$, in combination with Apaf-1, ATP and caspase-9, forms the apoptosomes and ultimately leads to activation of caspase- 3 and death of the target cell (24). AKT is a master regulator involved in transcriptional regulation of the antiapoptotic protein, $\mathrm{Bcl}-2$, which is critical in preventing cell death (25). In the present study, phosphorylation of AKT was decreased by colchicine treatment.

In conclusion, the present study demonstrates that colchicine may inhibit HT-29 colon cancer cell proliferation and induce HT-29 cell apoptosis through the mitochondrial pathway via activation of the p38 pathway.

\section{Acknowledgements}

The current study was supported by Hongkou District key project of Shanghai City Health Bureau. The authors would like to thank Biomedworld for their assistance with editing the manuscript.

\section{References}

1. Giovannucci E: Modifiable risk factors for colon cancer. Gastroenterol Clin North Am 31: 925-943, 2002.

2. Couzin J: Cancer T cells a boon for colon cancer prognosis. Science 313: 1868-1869, 2006.

3. François Y and Vignal J: Cancer of the colon. Etiology, physiopathology, diagnosis, development and prognosis, principles of the surgical treatment. Rev Prat 41: 1221-1225, 1991.

4. Chiu BC, Ji BT, Dai Q, Gridley G, McLaughlin JK, Gao YT, Fraumeni JF Jr and Chow WH: Dietary factors and risk of colon cancer in Shanghai, China. Cancer Epidemiol, Biomarkers Prev 12: 201-208, 2003.

5. Barrier A, Boelle PY, Roser F, Gregg J, Tse C, Brault D, Lacaine F, Houry S, Huguier M, Franc B, et al: Stage II colon cancer prognosis prediction by tumor gene expression profiling. J Clin Oncol 24: 4685-4691, 2006.

6. Jee SH, Moon SM, Shin US, Yang HM and Hwang DY: Effectiveness of adjuvant chemotherapy with 5-FU/ leucovorin and prognosis in stage II colon cancer. J Korean Soc Coloproctol 27: 322-328, 2011.

7. Dotan $\mathrm{E}$ and Cohen SJ. Challenges in the management of stage II colon cancer. Semin Oncol 38: 511-520, 2011.

8. Risinger AL and Mooberry SL: Taccalonolides: Novel microtubule stabilizers with clinical potential. Cancer Lett 291: 14-19, 2010.

9. Sivakumar G: Colchicine semisynthetics: Chemotherapeutics for cancer? Curr Med Chem 20: 892-898, 2013.

10. Risinger AL, Giles FJ and Mooberry SL: Microtubule dynamics as a target in oncology. Cancer Treat Rev 35: 255-261, 2009.

11. Jordan MA and Wilson L: Microtubules as a target for anticancer drugs. Nat Rev Cancer 4: 253-265, 2004.

12. Ravelli RB, Gigant B, Curmi PA, Jourdain I, Lachkar S, Sobel A and Knossow M: Insight into tubulin regulation from a complex with colchicine and a stathmin-like domain. Nature 428: 198-202, 2004.

13. Bhattacharyya B, Panda D, Gupta S and Banerjee M: Anti-mitotic activity of colchicine and the structural basis for its interaction with tubulin. Med Res Rev 28: 155-183, 2008.

14. Chopra A, Anderson A and Giardina C: Novel piperazine-based compounds inhibit microtubule dynamics and sensitize colon cancer cells to tumor necrosis factor-induced apoptosis. J Biol Chem 289: 2978-2991, 2014. 
15. Acharya BR, Chatterjee A, Ganguli A, Bhattacharya S and Chakrabarti G: Thymoquinone inhibits microtubule polymerization by tubulin binding and causes mitotic arrest following apoptosis in A549 cells. Biochimie 97: 78-91, 2014.

16. Rai A, Gupta TK, Kini S, Kunwar A, Surolia A and Panda D: CXI-benzo-84 reversibly binds to tubulin at colchicine site and induces apoptosis in cancer cells. Biochem Pharmacol 86: 378-391, 2013

17. Magalhães HI, Wilke DV, Bezerra DP, Cavalcanti BC, Rotta R, de Lima DP, Beatriz A, Moraes MO, Diniz-Filho J and Pessoa C: (4-Methoxyphenyl)(3,4,5-trimethoxyphenyl)methanone inhibits tubulin polymerization, induces $\mathrm{G} 2 / \mathrm{M}$ arrest and triggers apoptosis in human leukemia HL-60 cells. Toxicol Appl Pharmacol 272: 117-126, 2013.

18. Chiang NJ, Lin CI, Liou JP, Kuo CC, Chang CY, Chen LT and Chang JY: A novel synthetic microtubule inhibitor, MPT0B214 exhibits antitumor activity in human tumor cells through mitochondria-dependent intrinsic pathway. PLoS One 8: e58953, 2013.

19. Wu J, Yi W, Jin L, Hu D and Song B: Antiproliferative and cell apoptosis-inducing activities of compounds from Buddleja davidii in Mgc-803 cells. Cell Div 7: 20, 2012.
20. Wang X: The expanding role of mitochondria in apoptosis. Genes Dev 15: 2922-2933, 2001.

21. Zamzami N, Marchetti P, Castedo M, Hirsch T, Susin SA, Masse B and Kroemer G: Inhibitors of permeability transition interfere with the disruption of the mitochondrial transmembrane potential during apoptosis. FEBS Lett 384: 53-57, 1996.

22. Yan SL, Huang CY, Wu ST and Yin MC: Oleanolic acid and ursolic acid induce apoptosis in four human liver cancer cell lines. Toxicol In Vitro 24: 842-848, 2010.

23. Roux PP and Blenis J: ERK and p38 MAPK-activated protein kinases: A family of protein kinases with diverse biological functions. Microbiol Mol Biol Rev 68: 320-344, 2004.

24. Tsuruta F, Sunayama J, Mori Y, Hattori S, Shimizu S, Tsujimoto Y, Yoshioka K, Masuyama N and Gotoh Y: JNK promotes Bax translocation to mitochondria through phosphorylation of 14-3-3 proteins. EMBO J 23: 1889-1899, 2004.

25. Pugazhenthi S, Nesterova A, Sable C, Heidenreich KA, Boxer LM, Heasley LE and Reusch JE: Akt/protein kinase B up-regulates Bcl-2 expression through cAMP-response element-binding protein. J Biol Chem 275: 10761-10766, 2000. 